\title{
Editorial: The Power of Ideas
}

\author{
WENDY HARCOURT
}

I have been in a privileged position in the last 15 years working as Editor of Development, being able to read and respond to the many differing views of writers, researchers, civil society activists and policy-makers coming to grips with development, social justice and change from diverse locations and political positions. This special issue of the journal celebrating 50 years of the Society for International Development (SID) gives me an opportunity, with others, ${ }^{1}$ to reflect on the role the journal has played in shaping the development landscape.

From different angles, Development has looked critically at how to connect development policy and research with peoples' realities on the ground. As well as charting the course of mainstream development, the journal has given space to alternative thinking and practice. Over its long life Development has highlighted development policy that has worked with critical vision and resolve on human development, questioning the wisdom of a narrow focus on economic growth. It has also tried to underscore the problem of the increase in poverty, gender-based violence and social and economic insecurities, environmental loss and the degradation of cultures.

In fielding such debates, the journal over the last 50 years has been buffeted by many competing meanings of development. In this special issue of Development, I have invited some of the leaders of these debates to share their views. Their views range from dismissing the very concept of development as meaningless, dangerous, a racket or a mirage to celebrating development as a force for social and economic progress.

Tempting as it is to draw a neat divide between those that are for development and those that are against, I would say that the journal continually tries to capture the inbetween positions. Thus we emerge with an understanding of development that veers from a mainstream 'human development' focus to alternative visions for social transformation. There are also vital commonalities to be found. All who contribute to Development begin with grave concern for the serious problems of increasing economic, social and political inequalities. All struggle to understand how to work towards a collective good in today's rapidly changing context. And all aim to work from the ethical position of their own views and practices. But as each issue of the journal has shown, there is no uncontested blue print for development and there are many paths for responsible and committed engagement towards change. 
The journal has deliberately engaged different voices, from those involved in specific development projects as managers, researchers or bureaucrats to activists in community movement struggles who, despite their anger and dismay, are fighting back against powerful players. The journal has tried to bring out what is often hidden in descriptions of development documents and plans, and to question the privileged knowledge of the expert. Equally the journal has tried to go beyond rhetoric to listen to the actual experiences of communities, retold often by researchers who have had the time to reflect, think and make connections. Grand schemes for interventions have been questioned, along with any romanticism about the past or future. The journal has attempted to bring out the contradictions in the dialogues on well-meaning proposals and also the resistance to them. In this way the journal has been an important vehicle for sharing ideas, for building a politics of knowledge with multiple voices on a broad spectrum of issues impacting on peoples' lives, always with a sense of hope that through dialogue and dissent we will collectively bring about positive change.

As is evident in this special issue, the editorial line of Development cannot pretend to be neutral in its choice of themes or authors. The dialogues we have chosen to embrace particularly in the last years on sustainable livelihoods, movement building, civil society, gender inequality, public health, reproductive rights, cultural identity, new technologies, conflict, security, poverty and democracy, clearly try to confront established ways of understanding how and why global injustice persists. The message throughout the journal continues to be the need to disclose the frequent dishonesty of pushing technical fixes to deal with underlying causes of global economic and social justice. The journal is quick to expose the arrogance and disrespect that professionals in international relations, development bureaucracies and non-governmental organizations (NGOs) show at times for communities' experiences and knowledge. At the same time, it takes a stance in favour of those working to change inequalities in an increasingly complex global world.
The journal asks readers to build on the richness of different experiences and to embrace diversities rather than to search for highly technical solutions that could be applied to all societies. In this way, it differs fundamentally from the 'one size fits all' approach of institutions such as the World Bank and International Monetary Fund (IMF). Besides building respect for cultural diversity, the journal has tried to contribute to a form of modernity that acknowledges plural pathways and allows that we need time for ideas to take hold and bring about change. The journal has also aimed to give space for the explicit articulation of voices that are not often heard in the mainstream development as protagonists, both those working in the lower echelons of the machineries of development and those perceived as marginal to development decision making. The hard task, one that continues, is to bring these voices to the macrolevel and not dismiss them as micro-resistances, nor to obscure in the 'translation' process the realities of these lives, their environments and struggles in their places that make up the real global picture.

Harder still is how to ensure that there is a change in how people in power listen to others and recognize the need to change their own development conceptions and privileged paths. It is important that change is not reduced to just a cooption of ideas, so that the visions and hopes of people are taken and reduced to rhetoric or to superficial side shows while the real decisions are made elsewhere. Too often we see this repeated pattern of smoothing out the sharp edge of inequalities in programmes that have only instigated and perpetuated conflict, poverty, environmental loss and ill-health to plough on through millions of peoples' lives, environments and hopes. Change itself is multiple, and has to be meaningful for all engaged, for those who live in wealth and privilege as well as those who are living in violent need and vulnerability.

Development has tried to expose the power dynamics that determine injustices, as we are all caught in them. It is through the power of ideas that we help to understand how we and others are part of this relentlessly complex web of injustices that demand unravelling. It is in the collective 
process of unravelling that we can bring about change and create new social orders based on the inspiring visions that this journal will continue to celebrate.

\section{Note}

1 The entire issue of Development 50 SI is made up of reflections on 50 years of the power of ideas in development, beginning with the Upfront section series of short interviews. Other sections of the journal are devoted to historical records of some of the most visible contributions of people and programmes of the (SID) with a tribute to Barbara Ward, Michele Alacevich's charting of early debates of the Society, Louis Emmerij on the UN Intellectual History Project (a history of ideas) and the recollections of Richard Jolly on the North-South Roundtable, Ponna Wignaraja's and the International Secretariat's considerations of SID's programmatic paths, and the contributions of associate editors Nicola Bullard, Sanjay Reddy, Franck Amalric and Gillian Youngs on ways forward. In addition, there is a listing of 50 seminal articles published in Development over the years and a reprinting of a selection of articles for readers to see the power of ideas as they evolve. Ten years ago, Development Vol. 40, No. 1 reprinted other key articles celebrating four decades of SID, therefore the selection here is somewhat biased to more recent years. This issue of Who's Who records the names of the international office bearers who carried SID as an institution forward in the last 50 years. Acknowledegment and thanks must go to Palgrave Macmillan for their generosity in providing the resources to make this fifth issue of Vol. 50 of Development possible. 